Revista de la red interuniversitaria de estudios sobre las literaturas rioplatenses contemporáneas en Francia

$18 \mid 2018$

El río y la ciudad

\title{
Los humedales invisibles en textos de Saer y Wernicke
}

\author{
Leonardo Senkman
}

\section{OpenEdition}

Journals

Edición electrónica

URL: http://journals.openedition.org/lirico/5609

DOI: 10.4000/lirico.5609

ISSN: 2262-8339

Editor

Réseau interuniversitaire d'étude des littératures contemporaines du Río de la Plata

\section{Referencia electrónica}

Leonardo Senkman, "Los humedales invisibles en textos de Saer y Wernicke », Cuadernos LIRICO [En línea], 18 | 2018, Puesto en línea el 09 octubre 2018, consultado el 01 mayo 2019. URL : http:// journals.openedition.org/lirico/5609; DOI : 10.4000/lirico.5609

Este documento fue generado automáticamente el 1 mayo 2019.

\section{(c) $(1) \odot$}

Cuadernos LIRICO está distribuido bajo una Licencia Creative Commons Atribución-NoComercialSinDerivar 4.0 Internacional. 


\title{
Los humedales invisibles en textos de Saer y Wernicke
}

\author{
Leonardo Senkman
}

\section{La costa en textos de Saer}

1 La costa santafesina es espacio narrativo en importantes textos de Saer, a pesar de que los humedales fluviales en "la zona" donde creció y vivió su juventud el gran escritor del litoral están bastante borrados. Graciela Villanueva ha iluminado exhaustivamente la trama textual, intertextual y metafórica del río en textos de Saer ${ }^{1}$. Mi intención es indagar en los modos en que los humedales de esa zona -afluentes, riachos, arroyos, riberas, orillas y otros cauces de agua- aparecen mencionados más como signos metatextuales -y a menudo espacios de revelaciones dramáticas- que como protagonistas de las narraciones.

2 El territorio comprendido por una vasta área que, trazando una línea imaginaria, une las ciudades capitales de Santa Fe y Entre Ríos, siguiendo el río Paraná hasta su desembocadura en el estuario del Plata, integra casi $400 \mathrm{~km}$ de humedales que hasta hace pocas décadas eran invisibles para casi todos, no obstante que sus fluidos circunvalan los mayores aglomerados poblacionales de Argentina ${ }^{2}$.

3 Si “Amazonia es una construcción discursiva”, según Ana Pizarro ${ }^{3}$, glosándola me permito proponer que, a pesar de sus diferencias, también el discurso sobre este vasto espacio de humedales del complejo fluvial litoral del Paraná debería superar apenas el nivel descriptivo hidrográfico. Su presencia invita a interrogarnos acerca de la importancia histórica, cultural y ambiental de una zona fluvial de América Latina donde se cruzan la modernidad de la inmigración europea con estructuras míticas, redes misteriosas de símbolos autóctonos y un imaginario frondoso en torno de sus grandes ríos. También el alineamiento de las lomadas o cuchillas entrerrianas despierta la imaginación al provocar el escurrimiento de las aguas y su flujo en cuencas, cursos de riachos y arroyos en los valles de origen fluvial, estableciendo la divisoria de aguas de los ríos Paraná y Uruguay. 
4 Sabemos que estos humedales fluviales aislaron físicamente a Entre Ríos del resto del país; escasos caminos y casi ninguna ruta recorrían la provincia hasta bien entrados los años 60. Habitantes de Santa Fe como Saer, y entrerrianos como yo, nos movilizábamos en barcazas, lanchas, balsas, franqueando los numerosos brazos acuáticos, para trasladarnos a la provincia vecina. La construcción del Túnel Subfluvial en 1969, del complejo ferrovial Zárate-Brazo Largo a mediados de la década de 1970 y el enlace Victoria-Rosario inaugurado en 2003, produjeron un primer impacto de visibilidad pública en la sociedad regional y del litoral argentino. En esos años Saer ya había emigrado a Francia, y cuando en 1991 publicó El río sin orillas. Tratado imaginario, el Paraná no fue pensado como protagonista principal, sino el Río de la Plata. A pesar de que el relato integra también a las "provincias linderas", a través de remontar río arriba desde el Delta hasta "la Zona”, y que Saer narra un paisaje ribereño de ríos y arroyos en sus primeros relatos, sorprende que en El río sin orillas sean descriptos desde su exterioridad, prescindiendo acudir al "tratado imaginario" prometido para narrarlos. Como si cumpliera avant la lettre su prevención en el relato "Balnearios" al advertirnos de la mirada desdeñosa del río cuando se lo contempla desde la costa: "Nos paramos frente al mar, que nos contempla. Pero estamos siempre al costado del río que pasa sin mirarnos, desdeñosamente"4.

Sin embargo, Saer gustaba El agua y los sueños, de Gastón Bachelard, y recuerdo que en una de sus visitas a la casa de Juan L. Ortiz, que frecuentábamos hacia 1964, comentó aquel fragmento del filósofo francés sobre la campaña ondulada, en el valle de su infancia, que Juanele se complacía releer en voz alta de la edición francesa:

El sitio en que se ha nacido es menos una extensión que una materia; es un granito o una tierra, un viento o una sequedad, un agua o una luz; gracias a él nuestro sueño cobra su sustancia justa. Soñando cerca de un río he consagrado mi imaginación al agua, al agua verde y clara, al agua que pone verdes los prados. No puedo sentarme cerca de un río sin caer en una profunda ensoñación, sin volver a encontrarme con mi dicha. [...] Y en mi ensoñación no es el infinito del mar lo que encuentro en las aguas, sino la profundidad del rio. ${ }^{5}$

6 La ensoñación acuática en los relatos de Saer alimenta la sustancia narrativa y simbólica sobre su costa de Rincón, Colastiné, Santa Fe y el puerto, pero, a diferencia de Bachelard, ella no se abisma en la profundidad del río ni en sus humedales aledaños. A pesar de que las aguas humedecen sus mejores textos, y que es acertada la observación de Oscar Brando de que "ejemplos de aguas regeneradoras, naturaleza, limo de lo real, van amasando personajes y relato en su juego creador", el río funge como imagen tópica de la costa en textos de Saer. Al escritor le permitió pensar la temporalidad, narrar identidades "a medio borrar" y escribir bellamente sobre sensaciones de algunos protagonistas ${ }^{6}$.

7 El río sin orillas se lee muy frecuentemente como cartografía hidrográfica, y el fluir del agua en los humedales del litoral y en sus grandes ríos no siempre cabrillea ante los ojos del lector. A veces su ensayo invita a ser leído como compendio de geografía, humana, física, descripción relatada para lectores europeos. Ilustrativo resulta el relato del trayecto del viaje en ómnibus de Saer desde Buenos Aires a Paraná:

Santa Fe, Buenos Aires, Entre Ríos: provincias linderas. Ciertas líneas de colectivos unen las tres capitales. En el servicio diurno hay un ómnibus que sale a la una de Buenos Aires y llega a las ocho y media a Paraná, con una parada de veinte minutos en San Pedro y otra en la terminal de ómnibus de Santa Fe. Después de rodar durante horas por la cinta chata de la autopista, el colectivo cruza el puente carretero sobre la laguna Setúbal, costea las cañadas pantanosas que se extienden del otro lado de la laguna, atraviesa el puente sobre el río Colastiné, rueda sobre el asfalto delgado de la isla Verduc, se abisma en los tres kilómetros del túnel 
subfluvial, un poco brumoso a causa de los gases que despiden los caños de escape, y saliendo por la otra punta a la provincia de Entre Ríos, trepa ya semivacío por haber dejado una buena parte del pasaje en Santa Fe, por las barrancas del Parque Urquiza en dirección a la terminal de ómnibus de Paraná. ${ }^{7}$

8 Sin embargo, el narrador abandona esa visión externa de los humedales cuando relata sus sensaciones en un fortuito encuentro en la costa solitaria que lo conmueve hondamente. Apoyado sobre un sauce a la orilla de un curso de agua, en una calurosa siesta de octubre, Saer siente idéntica sensación de frescura mientras mira a una mujer cincuentona refrescarse en el agua; ese encuentro acontece en un humedal, no en una playa, en

una larguísima extensión de arena amarilla; sino un reducido semicírculo arenoso de unos cincuenta metros de diámetro -la orilla- formado, no por las vericuetos del Río de la Plata, ni de los grandes ríos que lo forman, el Paraná y el Uruguay, sino por el recodo perdido de algún afluente, la curva de un curso de agua que, a pesar de sus cincuenta o sesenta metros de anchura y sus cinco o seis o diez o quince de profundidad en el medio, a nadie se le ocurriría llamar río. (p. 211)

9 En esa orilla distraen al relator voces de niños y murmullos de "gente pobre" del lugar que se acercaban a la ribera: entonces ve a los dos niños a caballo, montados a pelo junto a su abuela que los acompañaba, y enseguida entran al agua para aliviar el calor de la siesta. Sin embargo, la orilla, no el agua, desaparece del relato que Saer transforma literariamente en una escena de correspondencia de sensaciones placenteras entre dos seres muy distintos que recién ahora se conocen en ese simultáneo goce del narrador contando cómo sienten también sus piernas idéntica sensación de caricia líquida al descubrir a la mujer cuando apenas se humedece hasta las rodillas:

Cuando los pies de la mujer entraron en el agua, una sensación súbita de frescura, intensa y deliciosa, me recordó la existencia de los míos y los trajo al primer plano de mis sensaciones. Y a medida que la mujer iba adentrándose en el río, y el nivel de agua iba cubriendo sus tobillos, sus pantorrillas hasta llegar a la rodilla, la sensación de frescura iba subiendo también por mis propias piernas, gratificándome con esa caricia líquida que, aunque no menos indefinible que el gusto del apio, y aunque el estímulo actuaba sobre una piel que no era la mía, no me costaba nada reconocer de inmediato. (p. 216-217)

Pero bien pronto esta narración de experimentar mutuas sensaciones con la mujer remite al lector no a la costa de un humedal santafesino, sino a una honda digresión reflexiva metatextual de Saer sobre el fragmento II de Heráclito, según el filósofo Sexto Empírico, aquel representante griego del escepticismo pirroniano:

La mujer que entraba en el río me iba mostrando, a medida que se internaba en el agua, el espejismo tenue de lo individual. Gracias a ella, el fragmento más conocido de Heraclito, "Los que entran en los mismos ríos se bañan en la corriente de un agua siempre nueva", que vino a mi memoria mientras la contemplaba fumando a la sombra del sauce[...] (p. 218)

11 Tal estrategia narrativa de Saer, quien prefiere nombrar la semejanza de sensaciones en la costa al tiempo que soslaya la irreductible otredad del paisaje fluvial, culmina al glosar a Heráclito: "Es posible que el río cambie continuamente, pero siempre es uno y el mismo el que penetra en él“" (p. 218). Más aun: si Saer reflexiona inmediatamente de que "el fin del arte no es representar lo Otro, sino lo Mismo." (p. 218), el lector atento se sorprende que para el autor de El río sin orillas sus aguas discurran sin color local, a pesar de reconocer matices cromáticos diferentes: "y que el tinte de la superficie cambiaba al cabo de varios minutos" (p. 219), mientras contemplaba las aguas desde una lancha. 
Saer escribe el libro convencido de que el paisaje fluvial narrado en su tratado imaginario es completamente contingente:

Los grandes ríos que forman el de la Plata, multiplicándose a medida que bajan del norte, y que configuran lo que se llama el litoral, no tienen nada de exótico y son el resultado de una serie de contingencias geológicas, geográficas y humanas en las que, por debajo del color local, el Logos común prosigue el soliloquio de su empastamiento con el mundo. (p. 219, énfasis mío)

13 Ya muchos años antes, en la primera versión del comienzo de su novela La ocasión (1988), redactada a partir de 1961, leemos ecos de esa arcaica contingencia geológica:

Ha de haber habido un tiempo, difícil de medir, en el que en esta tierra no había nada: ni las bestias, ni los indios, ni los árboles. Y después, de a poco, han debido brotar, del agua, las islas, una tierra homogénea, sin detritus, sin huesos, una costra barrosa, neutra. Después ha de haber habido un tiempo de vida grumosa, larval, sin distinciones. Un gran pantano de vida, todo a la misma altura, en la misma fase: la vida viscosa, ciega, móvil [...] ${ }^{8}$

14 Sin embargo, Saer comprendía bien la necesidad de nombrar en El río sin orillas lo particular de los brazos de agua y afluentes del río antes de su empastamiento con el mundo. A tal fin acude a otra fecunda estrategia suya: narrar biografía, vida y poética de Juan L. Ortiz, a quien reconoce no sólo como gran poeta sino que lo admira porque "supo captar mejor que nadie la apariencia particular y cambiante de esos ríos" (p. 223)

Así confiesa Saer su necesidad de acudir a Juan L. Ortiz: "Es obvio que no se puede hablar de estos ríos sin evocar su figura y su poesía, que se confunde con ellos [...]. Juan Laurentino Ortiz, a quien todo el mundo llamaba Juan L., pasó prácticamente su vida entera auscultando ese laberinto de agua". E, inmediatamente, Saer traza la hidrografía litoraleña de "ese laberinto", pero sin abandonar una mirada topográfica. Para empezar, ubica en el mapa a la Gualeguay de Juanele:

La ciudad de su infancia puede ser considerada, por su posición geográfica, como la matriz o el ombligo de la región fluvial, ya que se encuentra justo en la mitad de la base del triángulo invertido que trazan el Paraná y el Uruguay, cuando, reuniéndose en el vértice del Delta, forman el estuario. Equidistante a vuelo de pájaro de los dos afluentes, un poco más alejado de la desembocadura, su pueblo natal, Puerto Ruiz, domina el triángulo isósceles que forman los lados de agua. La multiplicación de ríos, riachos, arroyos, esteros, lagunas, pantanos, que ya desde el sur del Brasil y desde el Paraguay empiezan a converger hacia el sur, en las proximidades del estuario se vuelve vertiginosa. (p. 223)

Luego, Saer alterna su descripción física con la toponimia de localidades urbanas entrerrianas, finalizando en una suerte de cartografía del estuario del delta.

Como su nombre lo indica, todo el perímetro de la provincia de Entre Ríos es acuático, y su territorio entero está surcado de ríos y de arroyos que, más que en otras provincias del litoral, han preservado la toponimia indígena: Nogoyá, Gualeguay, Villaguay, Nançay, Gualeguaychú, Mocoretá, Guayquiraró. Para formar el Delta, el Paraná se desgaja en brazos innumerables, el Paraná Pavón, Paraná Ubicuy, el Guazú, el Miní, el Paraná de las Palmas. Las colinas entrerrianas, la proliferación acuática, y la llanura a partir de la orilla oeste del Paraná, las islas aluvionales y chatas del Delta, el estuario ilimitado: de eso está compuesto el lugar, que él transformó en paisaje y en entrecruzamiento cósmico, en el que nació y vivió Juan L. Ortiz. (p. 223-224)

17 En el acto de escribir sobre los fluidos en la poesía de Ortiz, mientras va narrando sobre un humedal del Litoral, pareciera que la estrategia narrativa escogida por Saer le permitiría una diseminación de su propio ser, exactamente con la misma acepción 
hermenéutica que tenía el acto de diseminación del ser de Flaubert, a quien cita metatextualmente en una digresión a propósito de una carta del autor francés enviada a Louise Colet. (p. 209)

Y al recordar el paisaje de humedales y entrecruzamiento cósmico (una cosmogonía fluvial mejor enunciada que narrada), Saer relata con sensibilidad e imaginación el nacimiento de una isla aluvial, a la que vio emerger desde la barranca paranaense en el jardín de la casa de Juan L.

Como la colina ubicua y borrosa de la cosmogonía egipcia que, brotando del agua, inaugura el mundo, esa islita apareció un buen día -o la vimos por primera vez, como el cráneo redondo y oscuro de un recién nacido saliendo desde el vientre de su madre- a finales de los años cincuenta, desde la barranca, no lejos de la casa de Juan L. Ortiz: al principio debió haber sido una agitación leve de la corriente, que el ojo inexperto debió tomar por un remolino, formada bajo el agua por la resistencia de los depósitos aluvionales, hasta que por fin, alcanzando la superficie, habiéndose acumulado lo bastante como para llegar a ras del agua, una protuberancia marrón y lustrosa emergió al exterior y empezó a crecer. (p. 230)

La última vez que Saer volvió a ver esa isla fue un día de la primavera de 1989, cuando ella se había transformado "más que isla, [en] un arquetipo de isla", comprobando admirado el desarrollo de aquella diminuta protuberancia fangosa que vio nacer frente a la casa de Juan L. en 1960 (p. 230).

En las antípodas del discurso regionalista y telúrico fluvial mesopotámico, el descubrimiento de esa isla arquetípica del río le permite a Saer escribir un metadiscurso universalista del paisaje fluvial litoraleño; su lógica le dice que a consecuencia de la sedimentación constante y de la corriente de aguas, vientos y estaciones, "también esta isla podría, para desbaratar todo exotismo, demostrar que lo típico de un lugar no es más que el resultado de una combinación propia y puramente contingente, de algunas leyes físicas y biológicas universales" (p. 230-231; énfasis mío).

21 Sin embargo, al desbaratar todo exotismo regional y localismo literario, rescatando únicamente lo contingente del paisaje fluvial, a diferencia de Ortiz, Saer elude tomarle ese pulso muy particular con ciclos de crecientes y bajantes que conforman las fases de inundación y sequía, ineludibles pulsiones del paisaje de humedales del Litoral argentino, muy distinto de esa indiferencia del protagonista ante la inundación del río en la primera versión de "Fragmentos". Cataclismo que deja también indiferente a Pichón en la versión final del relato "A medio borrar", en el que siempre "sigue subiendo el agua ciega y confusa" de la crecida y borra no sólo toda referencialidad geográfica del río que uniformiza el espacio urbano, sino también "sepulta nuestra memoria e identidad"

No se trata de criticar al narrador santafesino porque no auscultó el laberinto fluvial con ojos de Juan L., mucho menos con ojos de geólogo o geógrafo, en vez de escribir su tratado imaginario. Pero nos quedamos con las ganas de leer en El río sin orillas, además de metatextos que glosan a otros sobre la historia, cultura y geografía del Río de la Plata, también disfrutar de una fábula cosmogónica y poética del milenario complejo fluvial litoral del Paraná y su sistema de humedales trans-provinciales.

La lectura del tratado imaginario de Saer no imagina los flujos de agua del corredor fluvial Paraná-Paraguay que integran regiones con distinta historia geológica, ecológica, humana y cultural, funcionando como corredor térmico y biogeográfico de diferentes modalidades de vida ${ }^{10}$. 

ro al que, finalmente, no puede representar porque siente que la orilla es imprecisable y se le desvanece, como una incansable disolución de elementos. Escribe Chejfec:

Desde la costa se ve el río y se ingresa en él. En un punto, la costa sería más el río de Saer que el mismo río, en la medida en que se somete mejor a los requisitos de representación de este autor. ¿Dónde comienza o termina el agua? El borde del río en sus distintas manifestaciones es un leit motiv de los relatos de Saer. Son descripciones muy detalladas que apuntan sin embargo a referir una dificultad; la orilla es imprecisable: se muestra como una incansable disolución de elementos: asfalto desgranado, arena que se extingue, hormigón carcomido, etcétera. La idea de confusión o mezcla continua e imposible, si bien controlada por una fuerza ajena, está en el centro de las experiencias a las que se someten los protagonistas de Saer" ${ }^{13}$.

Efectivamente, en la versión borrador de La ocasión, cuando el relator cruza el sendero hacia la costa, entre aromos y pájaros gorjeando a su paso montado a caballo, describe una orilla casi imprecisa:

Llegué a la costa amarilla. Del otro lado, en la orilla barrosa, se movían densos, como cegados, los yacarés, de la orilla al agua y del agua a la orilla. Parecía como 
que el barro ondulara. [...] El tostado me esperó en la orilla, paciente, sin manea, mirando en dirección a la costa de enfrente, el barro escamoso y móvil. ${ }^{14}$ en el rancho, no cesa desde hace seis años el duelo por la muerte de su hijo y sólo contempla la figura antropomórfica del muchacho en el árbol lleno de limones; cuando Wenceslao se da un chapuzón, lo único que ve en la oscuridad subfluvial son imágenes fantasmagóricas de la nada, la nada del hijo en el fondo negro silencioso del río, muy diferente al silencio subacuático, salvo imágenes de mariposas nocturnas revoloteando en el farol de su rancho, cuyos zumbidos se mezclan onomatopéyicamente con el rumor de agua del río: "Era vea un solo ver agua. Agua y después más nada. Más nada. Aparece en eso una islita"16. Apenas leemos unos pocos vocablos náufragos de un cataclismo con los cuales Saer recomienza la narración, enmudecida por la mancha negra del luto que ahoga las palabras.

Resumiendo: cursos de agua sin orilla, la costa de la Zona Colastiné Rincón de Saer se convierte en un amasijo líquido de lo indistinto, que en El entenado (1983) alcanzaba una figuración mítica, invitando al lector a descifrar la ribera en clave cosmogónica de un litoral viscoso, pastoso de agua y barro, pero genésico.

\section{La ribera de Wernicke}

Si la irrealidad del paisaje de islas y costas en textos de Saer muestra una vida recién nacida o el pastoso material en estado bruto a la vera de humedales en Santa $\mathrm{Fe}$, el protagonista porteño en La ribera (1955) de Enrique Wernicke se aísla, en 1945, en la costa de una zona semi urbanizada, a pocos kilómetros de Buenos Aires.

La novela logró diseminar el "aura Wernicke", un estilo de laconismo y concisión que en los años sesenta fue muy apreciado, también por el mismo Saer ${ }^{17}$. Recluido en la zona de Vicente López, aledaña al Río de la Plata, Eduardo (alter ego de Wernicke) arriba como un ex-corresponsal durante la guerra civil española. Separado de su esposa y de un hijo, en Buenos Aires, que desprecia, renunció a la escritura y también a la política, en el año crucial para el triunfo del peronismo ${ }^{18}$.

A diferencia de los personajes de Saer, los protagonistas del relato de Wernicke no pertenecen al mundo fluvial. La crítica ha mostrado que la ciudad saeriana es propiamente una ciudad fluvial, y que el río surca igualmente ambos espacios, la costa y la ciudad: el río los une y separa, como el puerto ${ }^{19}$. En cambio, a pesar de que el relato está situado en la costa del Plata, los personajes de La ribera siguen siendo urbanos, no ribereños ni orilleros, y la naturaleza del río surge al lector elidida en la representación de su costa.

Durante los años 40, cuando transcurre la trama de la novela, la costa en Vicente López tenía playa natural en bajamar, usada como balneario de ancha franja de arena que llegaba hasta el límite de las mayores crecientes. Pero en La ribera, salvo la protagonista

Cuadernos LIRICO, 18 | 2018 
femenina que registra algunos nombres del paisaje de flora y fauna, desaparece la vida natural de una costa rodeada de prados, juncales, arroyos, lagunas, y una variedad de flores silvestres y muchas especies de aves. El narrador mira el río, pero la costa aparece a sus ojos llena de grandes toscas y otras piedras calizas porosas formadas de la cal de algunas aguas para la construcción.

A diferencia del río, hábitat natural de los personajes de Saer, la costa en Wernicke es un provisorio refugio donde Eduardo cree calmar la profunda angustia existencial urbana que lo acongoja. En la soledad compartida en aquella costa suburbana de Vicente López, poblada por inmigrantes y gente forastera de pasado dudoso, Eduardo descubre el modo de recuperar una vida auténtica gracias a su decisión de ser artesano y entrar en trato con gente sencilla, como Nono, quien también busca refugio en esa zona, huyendo de un conflicto con propietarios de quintas. A pocos metros de la costa, Eduardo trabaja independiente con sus manos, cincelando y pintando figuras de soldaditos de plomo en la misma casilla donde vive su vínculo con Susana, la ayudante adolescente en el taller artesanal, y pronto su amante.

A diferencia de los ranchos en la costa santafesina en relatos de Saer, la costa suburbana de Vicente López, cercana al Delta, no sólo tenía orillas y límites definidos en una zona de terraplenes y terrenos loteados para vivienda precaria como la de Eduardo, sino también con acceso fácil a Buenos Aires, vía ferrocarril (actual ramal Retiro-Tigre del ferrocarril Mitre).

Vivo en la ribera. Mi casa da frente a una estrecha calle de tierra que corre paralela a un alto terraplén de ferrocarril. Los fondos de mi terreno son como el mismo fin de la tierra porque dan de boca, entre abruptas toscas, contra el río. El terraplén del ferrocarril es un muro inaccesible que nos tapa la vista de la ciudad. El horizonte del río, por lo contrario, nos invita a todas las ansias. Necesariamente, mi paisaje me niega la amistad cercana y me entrega a las ridículas apetencias de todos los que sueñan imposibles [...]. El edificio que habito es uno de los tantos, típicos de la ribera: paredes de tabla machimbrada, techo de cinc. Cuatro pilares de ladrillos levantan los esquineros a un metro del suelo, en prevención de las crecientes.

Se entra en mi casa por un costado del lote. Y de quererlo, se continúa por una especie de camino hasta las grandes toscas del río. Antes, mirando al pasar, de lado, se ve un patio de tierra sombreado de mimbres y sauces donde una casilla mucho más levantada, mucho más vieja y decrépita, me sirve de taller. Hace apenas unos meses que estoy aquí; pero ya me he hecho a vivir sobre la costa. Bueno, he conocido esta ribera desde niño: nací en la loma de Vicente López ${ }^{20}$.

Contemplar la ribera le brinda al angustiado Eduardo una profunda calma mientras alterna sus cavilaciones mirando a la lejanía el río con el trabajo artesanal:

Saqué mi silla de paja y en un rincón habitual cebé mis mates mirando el río. Desde aquí se aprecia bien la línea de la costa. Las ramas de los sauces, apenas verdecidas, no llegan a tocar el suelo y forman un marco perfecto para mirar la mañana y la lejanía del agua. Uno mira, se distrae y siente como si goteara la vida (p. 10).

Sin embargo, Eduardo no se engaña de que su refugio en la costa no es sino un transitorio hábitat para un fugitivo urbano, angustiado, que no termina de saber nunca qué quiere ser.

Hoy soy un hombre de la ribera que se arremanga los pantalones para no embarrarse las bocamangas. Soy más feliz. Puedo, al menos, llegar a ser más feliz. Reconozco, sin embargo, que hasta la más completa paz que llegue a brindarme esta existencia tendrá un perfume casi desvanecido de desastre. Porque los sauces, el río, el cielo, el solitario ajetreo de mis manos, no bastan para darme el sentido del hombre (p. 34). 
41 La decisión de Eduardo de abandonar Buenos Aires y refugiarse en la ribera del Plata no tiene nada del gesto romántico de quien huye de la ciudad para ilusionarse y vivir lúdicamente en una Arcadia Feliz, tal como Wernicke imaginó al personaje de su bucólico relato rural en su anterior libro, La tierra del bien-te-veo (1948), ubicado en el mundo de la infancia. Ese lírico texto invita a ser leído jugando, al decir de Eduardo Romano ${ }^{21}$. Pero también en otros textos de ambiente campero, Chacareros (1951), la naturaleza está elidida en la poética narrativa de Wernicke, muy lejos del relato ruralista ${ }^{22}$, y a quien tampoco le interesaba oponer el interior del país al mundo urbano de Buenos Aires ${ }^{23}$. Juan, el concientizado obrero comunista de La ribera, vive semi clandestino en Vicente López y convence a Eduardo de salir de su indiferencia socio-política. Le confía una riesgosa misión de propaganda junto a otros camaradas en Buenos Aires contra el gobierno militar de la revolución nacionalista, pero la célula termina siendo reprimida y todos encarcelados en ese fatídico año 1945. De modo semejante a numerosos intelectuales comunistas en crisis, Eduardo pensaba que el compromiso político podría ayudarle a sobrellevar su angustia existencial. Pero a diferencia de ellos, luego de su excarcelación, se convence definitivamente de que tiene que abandonar la política, no obstante que camaradas antiperonistas adhieren a la Unión Democrática (p. 158). Eduardo retorna totalmente decepcionado a la costa en Vicente López. En la última parte de la novela, el río y sus humedales desbordados son transformados por el narrador en alegorías de una temida inundación: su naturaleza no sólo será fluvial durante la crecida del río, sino metáfora de muerte por la derrota política que implica el triunfo del peronismo, y además porque preanuncia el suicidio de Susana, la joven amante que esperaba un hijo no querido por Eduardo ${ }^{24}$.

No sorprende, pues, que en La ribera y en su otra novela, El agua (1968), el lector descubra analogías entre el acoso de la crecida, la violencia de la inundación y la desdichada sensación de frustración y anegamiento existencial de algunos personajes alucinados de Wernicke, como el anciano don Julio Blake quien, al comprobar los estragos de la sudestada, exclama: derrotado pero aún jubiloso por las aguas que todavía no han anegado completamente su casa: “¡Extraña felicidad! Pero auténtica”25.

Y no casualmente la trinidad río, borrachera de vino y angustia conducen a Eduardo a esta reflexión, sobre su fracaso de hallar sosiego mediante la adicción al alcohol y su autoexclusión en la ribera: "No hay paisaje, ocupación ni voluntad capaces de cambiarnos [...]. La ribera es un lugar de la tierra como cualquiera, mi oficio una ocupación que no logra renovar antiguos hábitos" (p. 34, énfasis mío) ${ }^{26}$.

Esa indiferenciación topográfica y la ubicuidad de la ribera se hacen patente en la confesión del narrador quien, alternativamente, va escribiendo un relato novelado -y asimismo un diario íntimo- sobre su vínculo totalmente distante con el agua: “como ese río que tenía delante que, a pesar de mojarme las piernas, sólo se me antojaba auténtico en la distancia de su horizonte" (p. 110) ${ }^{27}$.

Concluyendo: la costa se invisibiliza en La ribera de Wernicke y es sustituida por la crecida que la anega completamente ${ }^{28}$. A pesar de sus inmensas diferencias estéticas, los núcleos de sentido (el tiempo, el mito, la historia, la angustia existencial) en las ficciones de Saer, ubicadas en la ribera del Paraná, frente a Santa Fe, y las de Wernicke, en la costa suburbana bonaerense de Vicente López, eluden sumergirse en el río. Sus textos comparten una matriz de lectura de invisibilidad de las zonas de humedales, a pesar de 
que el relator se arrima a sus orillas en las ficciones La ribera y El río sin orillas. Ensayo imaginario.

\section{NOTAS}

1. Graciela Villanueva, “ ‘En un lugar arcaico y sin orillas'. Imágenes del río en la obra de Juan Jose Saer", Sergio Delgado, Alexis Chausovsky y Guillermo Mondejar (eds.), El horizonte fluvial. Coloquio en el País del Sauce, Paraná, EDUNER, 2017, p. 129-156.

2. Actualmente contamos con imágenes satelitales y distintos estudios hídricos. Ver I. M. Barberis, C. G. Ramonell, A. R. Giraudo y Z. Y. Marchetti, "Humedales de las cuencas fluviales del centro-este santafesino", en AA.VV, Inventario de los humedales de Argentina. Sistema de paisajes de humedales del corredor fluvial Paraná-Paraguay, Secretaría de Ambiente y Desarrollo Sustentable de la Nación, Ministerio de Agricultura, Ganadería y Pesca, República Argentina, Buenos Aires, 2013, p. 169-176. En internet: http://www.unsam.edu.ar/tau/sitio/wp-content/uploads/ inventario_humedales_parana_paraguay.pdf. Consultado el 3/9/2018.

3. Ana Pizarro, "Imaginario y discurso: la Amazonia", Revista de Crítica Literaria Latinoamericana, año XXXI, nº 61, primer semestre de 2005, Medford, TUFTS University, p. 59-74.

4. Juan José Saer, “Balnearios”, La Mayor. Argumentos, Buenos Aires, CEAL, 1982, p. 119-121.

5. Gaston Bachelard, El agua y los sueños. Ensayo sobre la imaginación de la materia, México, Fondo de Cultura Económica, 1978. Juan L. Ortiz leía la primera edición en francés: L'eau et les rêves, París, Lib. José Corti, 1942.

6. Oscar Brando, La escritura de Juan Jose Saer: la tercera orilla del río, Tesis de doctorado, Université Charles de Gaulle - Lille III, 2013, p. 125. Ver también Beatriz Sarlo, “Narrar la percepción”, Punto de Vista, $\mathrm{n}^{\circ} 10$, noviembre 1980, p. 34-47.

7. Juan José Saer, El río sin orillas. Tratado Imaginario, Buenos Aires, Seix Barral, 1991, p. 233. Todas las citas corresponden a esta edición.

8. Juan José Saer, Papeles de trabajo. Borradores inéditos, Buenos Aires, Seix Barral, 2012, p. 345.

9. Citamos de Juan José Saer, “A medio borrar”, La Mayor, op. cit., p. 57, 59 y 61.

10. Cfr. Sistema de paisajes de humedales del corredor fluvial Paraná-Paraguay, op.cit.

11. Juan José Saer, La grande, Buenos Aires, Seix Barral, 2005, p. 193.

12. Oscar Brando, La escritura de Juan José Saer , op. cit, p. 198.

13. Sergio Chejfec, “¿Dónde comienza o termina el agua?”, Transatlántico, $n^{\circ} 15$, Rosario, verano 2012/2013, Centro Cultural Parque España/AECID, p. 7.

14. Juan José Saer, "Documentos y Variantes de La ocasión (1961-1987)", Papeles de trabajo. Borradores inéditos, op.cit., p. 347.

15. Juan José Saer, Nadie nada nunca (1980), Buenos Aires, Seix Barral, 1995, p. 9 y 16.

16. Juan José Saer, El limonero real, Barcelona, Planeta, 1974, p.149.

17. Según Roberto Brando, "la modalidad de elipsis de Wernicke tuvo en Saer un silencioso seguidor, a pesar de que fue más explícito con la elusión trabajada por Antonio Di Benedetto" (op. cit., p. 13).

18. Para una introducción a la biografía y la estética del relato breve de Wernicke, ver: Elvio Gandolfo, prólogo a Enrique Wernicke, Cuentos Completos, Buenos Aires, Ed. Colihue, 2001.

19. Rafael Arce, “Un realismo de lo irreal: la imaginación material en la obra de Juan José Saer”, Anclajes, vol. 13, n 1, Santa Rosa, enero/junio 2009. 
20. Enrique Wernicke, La ribera (1955), Buenos Aires, Centro Editor de América Latina, 1967, p. 8-9, Todas las citas corresponden a esta edición.

21. Eduardo Romano, "Culminación y crisis del regionalismo narrativo", en Noé Jitrik (dir.), Historia crítica de la literatura argentina, vol. 9, Buenos Aires, Emecé, 2004; y también: Ismael Viñas, "Enrique Wernicke: la poesía en las chacras", Contorno n 5-6, septiembre 1955.

22. Nilda del Valle Palacios, "Proceso de lo rural en la narrativa de Enrique Wernicke", en Boletín del Instituto de literatura argentina e iberoamericana, vol. III, nº 3, 1967, Córdoba, Universidad Nacional de Córdoba.

23. Martín Prieto, “Escrituras de la 'zona' en Noé Jitrik (dir.), Historia crítica de la literatura argentina, vol. 10, Buenos Aires, Emecé, 2006.

24. Ver el análisis de Guillermo Martín Korn, “Tristezas del vino de la costa. Acerca de La ribera de Enrique Wernicke", Inti. Revista de literatura hispanoamericana, no 52-53, 2000; y Hebe Uhart, "Personajes femeninos en la obra de Enrique Wernicke", Liliana Lukin (coord.), Narrativa Argentina. Décimo encuentro de escritores Dr. Roberto Noble, Buenos Aires, Clarín, 1997.

25. Enrique Wernicke, El agua (1968), Buenos Aires, CEAL, 1994, p. 30. Ver el prólogo de Alfredo Rubione; también el análisis de Andrés Monteagudo sobre la metáfora de la muerte en la poética de Wernicke y la caracterización de sus personajes de una "literatura de náufragos, militantes escépticos, borrachos y viejos alucinados”, en: “Wernicke, escritor póstumo”, Miguel Votagliano (comp.), Boedo. Políticas del realismo. Buenos Aires, Recurso editorial, 2012, p. 223-236.

26. Ver el análisis de Martín Korn en "Tristezas del vino de la costa. Acerca de La ribera de Enrique Wernicke", op. cit.

27. Ver la relación íntima entre la novela La ribera y el diario Melpómene que Wernicke escribió a partir de 1937 a lo largo de toda su vida, diario que aún sigue inédito: Christian Estrade, “ Melpómene de Enrique Wernicke. Diario de un narrador", presentación en las Jornadas Diario y Ficción, Universidad de Grenoble, 2007. Reproducido en http://www.crimic.paris-sorbonne.fr/ actes/tl2/texte-liens2.htm. Ver también: Enrique Wernicke, "Melpómene inédito, (selección de Jorge Asís), revista Crisis, ํㅡㄴ 29, septiembre 1975.

28. No por casualidad Andrés Monteagudo finaliza su lúcido ensayo con la metáfora de la muerte y la purificación de la inundación: "hay un momento en que se vive la crecida de las aguas como algo sublime, con un gozo primigenio; pero a medida que el río crece y el agua moja y remueve la roña de la costa, el idilio se rompe, anega, inunda, ahoga, el río se lleva la vida..." (op. cit., p. 233).

\section{RESÚMENES}

El artículo indaga narraciones de Juan José Saer y Enrique Wernicke cuyos imaginarios y las zonas de sus diégesis son ficciones ubicadas en la ribera del Paraná o en la costa del Río de la Plata, pero cuyos núcleos de sentido (el tiempo, el mito, la historia) invisibilizan los humedales, a pesar que el relator se arrima a sus orillas en El rio sin orillas. Ensayo imaginario, y en La ribera.

L'article enquête sur les narrations de Juan José Saer et Enrique Wernicke. Leurs imaginaires et la zone de leurs diégèses sont des fictions localisées sur les rivages du Paraná ou du Río de la Plata. Cependant, leurs noyaux de sens (le temps, le mythe, l'histoire) rendent les zones humides invisibles malgré la proximité du narrateur des rivages dans El rio sin orillas. Ensayo imaginario, et La ribera. 
This article explores the stories of Juan José Saer and Enrique Wernicke. Their imaginative worlds and zones of diegesis are fictions located on the Paraná riverside or the Río de la Plata shore. Nuclei of meaning (time, myth, history) make the humid areas invisible, despite the authors approaching their riversides in El río sin orillas. Ensayo imaginario and La ribera.

\section{ÍNDICE}

Mots-clés: Juan José Saer, Enrique Wernicke, Paraná, rivage, Río de la Plata

Keywords: Juan José Saer, Enrique Wernicke, Paraná, riverside, Río de la Plata

Palabras claves: Juan José Saer, Enrique Wernicke, Paraná, orilla, Río de la Plata

\section{AUTOR}

\section{LEONARDO SENKMAN}

Universidad Hebrea de Jerusalen 